\title{
Evaluation of EPAS1 variants for association with bovine
}

\section{congestive heart failure [version 1; peer review: 3 approved]}

\author{
Michael P. Heaton (D1), Adam S. Bassett2, Katherine J. Whitman2, Greta M. Krafsur³, \\ Sang In Lee², Jaden M. Carlson², Halden J. Clark², Helen R. Smith, \\ Madeline C. Pelster², Veronica Basnayake4, Dale M. Grotelueschen², \\ Brian L. Vander Ley (iD)2
}

\footnotetext{
${ }^{1}$ U.S. Meat Animal Research Center, Clay Center, Nebraska, 68933, USA

2University of Nebraska-Lincoln, Clay Center, Nebraska, 68933, USA

${ }^{3}$ Anschutz School of Medicine, University of Colorado Denver, Aurora, Colorado, 80045, USA

${ }^{4}$ Neogen GeneSeek Operations, Lincoln, Nebraska, 68504, USA
}

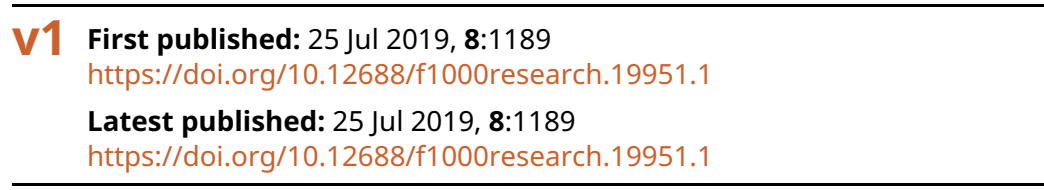

\section{Abstract}

Background: Bovine congestive heart failure (BCHF) has become increasingly prevalent in feedlot cattle in the Western Great Plains of North America. BCHF is an untreatable complex condition involving pulmonary hypertension that culminates in right ventricular failure and death. A protein variant of hypoxia-inducible factor 2 alpha (HIF2 $a$, encoded by the endothelial PAS domain-containing protein 1 gene, EPAS1) was previously reported to be associated with pulmonary hypertension at altitudes exceeding 2,000 m. Our aim was to evaluate EPAS1 haplotypes for association with BCHF in feedlot cattle raised at moderate altitudes $(1,200 \mathrm{~m})$.

Methods: Paired samples of clinical cases and unaffected controls were collected at four feedlots in Nebraska and Wyoming. Each pair (n =102) was matched for source, pen, breed type, sex, arrival date, and management conditions. Cases were identified by animal caretakers, euthanized, and diagnosis was confirmed at necropsy. Cases were derived from 30 different ranch operations, with the largest source contributing 32. Animals were tested for eight EPAS1 haplotypes encoding 36 possible different diploid combinations.

Results: The common, ancestral EPAS1 haplotype encoding HIF2a with alanine (A) at position 606 and glycine $(G)$ at position 610 was equally frequent in cases and controls (0.67). The EPAS1 variant haplotype reported to be associated with disease (encoding threonine $(T)$ at position 606 and serine (S) at position 610) was not enriched in cases compared with controls ( 0.21 and 0.25 , respectively). Frequencies of other EPAS1 haplotypes (e.g., encoding Q270, L362, or G671) were each less than 0.05 overall. McNemar's test with 45 discordant pairs showed the linked T606/S610 variant was not associated with BCHF $\left(\mathrm{OR}=0.73, \mathrm{CI}_{95} 0.38-1.4, p\right.$-value $\left.=0.37\right)$.

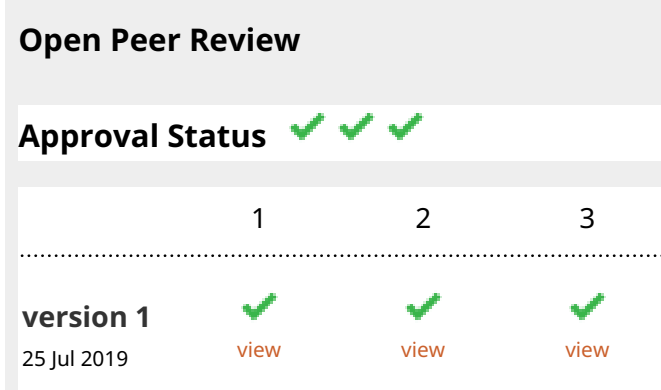

1. Donagh P. Berry, Teagasc, Fermoy, Ireland

2. Emily L. Clark ID, University of Edinburgh, Midlothian, UK

3. Franklyn B. Garry (iD), Colorado State University, Fort Collins, USA

Any reports and responses or comments on the article can be found at the end of the article. 
Conclusions: HIF2a polypeptide variants were not significantly associated with $\mathrm{BCHF}$ in feedlot cattle at moderate altitudes. Thus, a wider search is needed to identify genetic risk factors underlying this disease.

\section{Keywords}

Heart failure, cattle, EPAS1, HIF2A, brisket disease, pulmonary hypertension, feedlot

Corresponding authors: Michael P. Heaton (mike.heaton@ars.usda.gov), Brian L. Vander Ley (bvanderley2@unl.edu)

Author roles: Heaton MP: Conceptualization, Data Curation, Formal Analysis, Funding Acquisition, Investigation, Methodology, Project Administration, Resources, Software, Supervision, Validation, Visualization, Writing - Original Draft Preparation, Writing - Review \& Editing; Bassett AS: Investigation, Writing - Review \& Editing; Whitman KJ: Conceptualization, Investigation, Methodology; Krafsur GM: Conceptualization, Investigation, Methodology, Resources; Lee SI: Investigation; Carlson JM: Investigation, Writing - Review \& Editing; Clark HJ: Investigation, Writing - Review \& Editing; Smith HR: Investigation, Writing - Review \& Editing; Pelster MC: Investigation, Writing - Review \& Editing; Basnayake V: Investigation, Resources, Writing - Review \& Editing; Grotelueschen DM: Conceptualization, Funding Acquisition, Methodology, Project Administration, Resources, Supervision, Writing - Review \& Editing; Vander Ley BL: Conceptualization, Funding Acquisition, Investigation, Methodology, Project Administration, Resources, Supervision, Writing - Review \& Editing

Competing interests: The authors declare the following interest: co-author V.B. is a full-time employee at GeneSeek, a Neogen company that provides agrigenomic and veterinary diagnostic services. There are no patents, products in development, or marketed products to declare. These interests do not alter the authors' adherence to all the journal's policies on sharing data and materials.

Grant information: Funding for this research was provided by the USDA, ARS appropriated projects [5438-32000-033-00D] (MPH) and The University of Nebraska Great Plains Veterinary Educational Center [2162390003] (DMG, BLVL) and the Nebraska Beef Industry Endowment [2662390323001] (BLVL).

The funders had no role in study design, data collection and analysis, decision to publish, or preparation of the manuscript.

Copyright: $\odot 2019$ Heaton MP et al. This is an open access article distributed under the terms of the Creative Commons Attribution License, which permits unrestricted use, distribution, and reproduction in any medium, provided the original work is properly cited.

How to cite this article: Heaton MP, Bassett AS, Whitman KJ et al. Evaluation of EPAS1 variants for association with bovine congestive heart failure [version 1; peer review: 3 approved] F1000Research 2019, 8:1189

https://doi.org/10.12688/f1000research.19951.1

First published: 25 Jul 2019, 8:1189 https://doi.org/10.12688/f1000research.19951.1 


\section{Introduction}

Brisket disease has been known in the Rocky Mountain Region of Colorado and Utah for more than 100 years as a high altitude disorder characterized by severe ventral edema of the chest tissues ${ }^{1,2}$. In affected cattle, the reduced partial pressure of oxygen at high altitudes causes pulmonary hypoxia, vascular resistance, arterial remodeling, and pulmonary hypertension. As late as 1963, reports of brisket disease were limited to cattle grazed at altitudes greater than $2,100 \mathrm{~m}$, with a prevalence of $2-10 \%{ }^{3}$. This condition, attributed to "cor pulmonale', eventually causes right ventricular overload and enlargement, ultimately leading to heart failure. In 1976, a similar condition was reported in yearling feedlot cattle maintained at a lower altitude of 1,600 $\mathrm{m}^{4}$. Since the 1970's, bovine congestive heart failure (BCHF) has become increasingly common in feedlot cattle maintained at the low to moderate altitudes of the North American Plains (800 to $1,600 \mathrm{~m})^{5}$. However, it is uncertain whether hypobaric hypoxia is the underlying cause of $\mathrm{BCHF}$ in these cattle, and evidence suggests that left heart dysfunction may initiate $\mathrm{BCHF}^{6}$. Histopathological assessment of cardiopulmonary tissues obtained from affected cattle fattened at 544-1,420 m revealed significant ventricular fibrosis, abundant cardiac adipose depots, coronary artery injury, and pulmonary venous remodeling ${ }^{6}$. These features were phenotypically distinct from those of cattle with cor pulmonale at high altitudes. However, other evidence in similarly affected cattle $(1,369 \mathrm{~m})$ suggested death occurred prior to the development of advanced obesity $^{7}$. Thus, disease pathogenesis of BCHF in feedlot cattle maintained at the moderate altitudes remains unclear.

The impact of BCHF on animal mortality is substantial and appears to be increasing. Mortality in the U.S. and Canada has been estimated at 11 per 10,000 animals entering feedlots, with the rate doubling from 2002 to $2012^{5}$. Personal communication between authors (MPH and BLVL) and a Nebraska feedlot owner (G. Darnall) in 2018 indicated a BCHF prevalence as high as $7.5 \%$ in some single source lots of cattle. Affected cattle were typically bred and managed with the aim of achieving high carcass quality. For some affected producers in the Western Plains, BCHF is their single most costly health-related problem, with losses exceeding $\$ 250,000$ annually in individual operations, surpassing those from bovine respiratory disease. Consequently, reducing the impact of $\mathrm{BCHF}$ is a high priority for the cattle industry.

A potential genetic risk factor for BCHF was reported in 2015 for cattle with high-altitude pulmonary hypertension $(1,478$ to $2,618 \mathrm{~m})^{8}$. Angus cattle affected with pulmonary hypertension had a higher frequency of the endothelial PAS domain-containing protein 1 gene (EPAS1) encoding a hypoxia-inducible factor 2 alpha (HIF2 $\alpha$ ) double variant with threonine (T) at position 606 and serine (S) at 610 . This HIF2 $\alpha$ T606/S610 variant was proposed to have a dominant gain-of-function activity ${ }^{8}$. Subsequent whole genome sequencing analysis of EPAS1 in 19 breeds of U.S. cattle identified four additional HIF $2 \alpha$ variants encoded by EPAS1 (E270Q, P362L, A671G, and L701F)9. Together, these six amino acid variants comprised eight distinct polypeptide HIF $2 \alpha$ sequences. A rooted phylogenetic tree of these HIF2 $\alpha$ protein sequences provided a framework for evaluating their potential impact on BCHF in U.S. cattle ${ }^{9}$. In the present report, our aim was to evaluate EPAS1 haplotypes encoding HIF2 $\alpha$ protein variants for association with BCHF in feedlot cattle, raised at moderate altitudes. Here we show that the HIF2 $\alpha$ T606/ S610 variant encoded by EPAS1 was not associated with BCHF in feedlot cattle maintained at 1,200 $\mathrm{m}$ in the geographic region experiencing outbreaks. The results are important for understanding the disease mechanism and for future selection of breeding animals with reduced risk for BCHF.

\section{Methods}

\section{Ethical statement}

The experimental design and procedures used during this research project were approved by the Institutional Animal Care and Use Committee (IACUC) of the University of NebraskaLincoln (UNL) Experimental Outline Number 139. The UNL animal care program is accredited by the Association for Assessment and Accreditation of Laboratory Animal Care, registered with the United States Department of Agriculture, and assured by the National Institutes of Health Public Health Service Policy on Humane Care and Use of Laboratory Animals. The university meets these goals through review and approval by the IACUC before projects are initiated for any research and educational activities involving vertebrate animals, to assure compliance with all laws, regulations and rules governing the care and use of animals, and by continuing review and monitoring of approved studies.

No animals were housed at research facilities or cared for by researchers during this study. All animals were privately owned and located at commercial feedlot operations and managed according to their standard operating procedures (SOP), which includes euthanasia of terminal heart failure cases as recommended by the American Veterinary Medical Association (AVMA). All pen matched unaffected (control) animals were briefly sampled by collecting an ear notch and blood sample and returned to their pens without further involvement in the study. In every instance, efforts were made to ameliorate animal suffering for this incurable, untreatable congesting heart disease.

\section{Animals and study design}

Paired samples from 102 affected calves and their 102 unaffected matched penmate controls were collected from four private commercial feedlots during a 16-month period spanning January 2017 to April 2018. A sample size of 100 matched pairs was targeted based on the frequency of the EPAS1 T606/S610 variant in Angus cattle $(0.22)^{9}$. Together with Hardy-Weinberg assumptions, the proportion of discordant pairs having one or two copies of the dominant risk factor was expected to be 0.476 and achieve greater than $80 \%$ power to detect an odds ratio of 2.5 using a two-sided McNemar test with a significance level of 0.05 (PASS 2019 Power Analysis and Sample Size Software, version 19.0.2 (NCSS, LLC. Kaysville, Utah, USA).

Potential clinical cases were identified by experienced animal caretakers on horseback (pen riders) and segregated for treatment by moving to a hospital pen. This daily activity is part of the SOP for pen riders, i.e., to identify animals with any potentially serious health problems and move them to a dedicated treatment area. Terminal cases were euthanized by feedlot personnel based 
on clinical presentation. Euthanasia was accomplished with a well-placed bullet by trained feedlot personnel according to AVMA approved protocols, as part of the feedlot operation's SOP for terminally ill animals. The case definition included two or more clinical signs specific to BCHF: ventral and intermandibular edema ('brisket' and 'bottle jaw'), jugular vein distention and pulsation, ascites/abdominal swelling, and exophthalmia ('bug-eye') ${ }^{10,11}$. The case definition also included two or more non-specific clinical signs: dyspnea, abducted elbows, depression, drooped ears, intermittent watery orange diarrhea, tachycardia, exercise intolerance, open mouth breathing, and weight loss. Clinical signs increased with disease progression and in some cases, animals died naturally within 24 hours of clinical presentation, while other cases progressed over a period of days to weeks, and thus provided a window of opportunity to collect fresh samples immediately after euthanasia. Researchers were contacted by the feedlot operator when an animal became ill and needed to be euthanized. Researchers then travelled to the feedlot for sample collection. A presumptive diagnosis based on heart morphology and gross lesions was made at necropsy by animal caretakers (cases one to nine) and veterinarians (cases 10 to 102). Carcasses were enrolled in the study only if there was a postmortem presumptive diagnosis of congestive heart failure at necropsy.

Control tissue samples were collected from non-affected penmates matched for source, arrival date, gender, and breed type (based on source, coat color, horned/polled status, ear size and dewlap). The pen sizes ranged from 100 to 300 animals, and control animals were selected based on their willingness to be driven through the gate by riders on horseback. In two instances, the same control animal was inadvertently used as a penmate match for two clinical cases. None of the control animals developed clinical BCHF signs prior to harvest according to feedlot records and pen rider observations.

Tissue samples for genomic DNA isolation included V-shaped ear notches and EDTA whole blood collected by venipuncture. Squeeze chute devices at the feedlot facilities were used for sample collection with animals that were able to safely enter and exit the gates. Some affected animals were not able to safely enter the device and thus, their samples were collected immediately after euthanasia. The ear tissue was desiccated with granular $\mathrm{NaCl}$ in the field and stored at $-20^{\circ} \mathrm{C}$ upon return to the research facility (four to twelve hours later). The plasma and cellular fractions of EDTA whole blood were separated in the field by centrifugation for 10 minutes at $1,350 \mathrm{x} \mathrm{g}$, placed in liquid nitrogen immediately and stored at $-80^{\circ} \mathrm{C}$ upon return. Hearts, livers, blood, and ear notches from unaffected cattle were collected during federally-inspected beef processing at the U.S. Meat Animal Research Center abattoir from six purebred Angus heifers raised and fattened at $578 \mathrm{~m}$ and 15 purebred Angus cows maintained for breeding at $578 \mathrm{~m}$.

\section{DNA extraction and single nucleotide polymorphism (SNP) genotyping}

Unless otherwise indicated, reagents were molecular-biology grade. DNA from ear notches was extracted by standard procedures ${ }^{12}$. Briefly, hair follicles were shaved from the tissue and approximately one half of the ear notch was minced and suspended in $2.5 \mathrm{~mL}$ of a lysis solution containing $10 \mathrm{mM}$ TrisCl, $400 \mathrm{mM} \mathrm{NaCl}, 2 \mathrm{mM}$ EDTA, $1 \% \mathrm{wt} / \mathrm{vol}$ sodium dodecyl sulfate, RNase A (250 ug/ml; Sigma-Aldrich, St. Louis, Missouri, USA), $\mathrm{pH}$ 8.0. The solution was incubated at $55^{\circ} \mathrm{C}$ with gentle agitation. After one hour, $1 \mathrm{mg}$ proteinase $\mathrm{K}$ was added (SigmaAldrich) and the solution was incubated overnight at $55^{\circ} \mathrm{C}$ with continued agitation. The solution was transferred to a $15 \mathrm{ml}$ tube containing $2 \mathrm{ml}$ of a phase-separation gel (high-vacuum grease, Dow Corning Corporation, Midland, Michigan, USA) and extracted twice with one volume of phenol:chloroform:isoamyl alcohol $(25: 24: 1)$, and once with one volume of chloroform before precipitation with two volumes of $100 \%$ ethanol. The precipitated DNA was washed once in $70 \%$ ethanol, briefly air dried, and dissolved in a solution of $10 \mathrm{mM}$ TrisCl, $1 \mathrm{mM}$ EDTA (TE, $\mathrm{pH}$ 8.0). A single multiplex matrix-assisted laser desorption/ionization time-of-flight mass spectrometry (MALDI-TOF MS) assay was used for the six EPAS1 missense SNPs, as previously described ${ }^{9}$. Assay design and genotyping was performed at Neogen GeneSeek Operations (Lincoln, Nebraska, USA). The iPLEX Gold technology and MassARRAY DNA analysis system with MALDI-TOF MS (Agena Biosciences Inc., San Diego, California) was used according to the manufacturer's protocol. Briefly, genomic DNA was amplified in microtiter plates using the supplied reagents. After the PCR, excess nucleotides were dephosphorylated by shrimp alkaline phosphatase. This was followed by a single base extension reaction in which a mix of oligonucleotide extension primers was added together with an extension enzyme and massmodified dideoxynucleotide terminators. The extension primers are designed to anneal directly adjacent to each SNP site and were extended and terminated by a single complementary base. The extension products were desalted and transferred from the microtiter plate onto a chip array, where they crystalize with a pre-spotted MALDI matrix. The chip array was loaded into the mass spectrometer, where the analyte crystals were irradiated by a laser, inducing desorption and ionization. The positively charged molecules accelerate into a flight tube towards a detector. Separation occurs by time-of-flight, which is proportional to the mass of the individual molecules. After each laser pulse, the detector records the relative time of flight for each extension product and the results were displayed on the machine. Genotypes were scored automatically and summary reports were generated.

\section{Assigning haplotype phase and statistical analyses}

As previously reported, a maximum parsimony phylogenetic tree was used to unambiguously phase protein variants encoded by EPAS1 haplotypes? ${ }^{9}$ Haplotype-phased protein variants were unambiguously assigned in individuals that were either: 1) homozygous for all six variant sites, or 2) had exactly one heterozygous variant site. The phylogenetic tree was also important for providing a framework for chi-squared testing. The association of EPAS1 haplotype combinations (diplotypes) with clinical disease was evaluated with two tests. The first was a Pearson's chi-squared test since it met requirements for appropriate use: nominal categorical data, large sample size $(n=204)$, and independence of observation assumption (cases were mutually exclusive of controls). There was a small deviation of the 
assumption that each subject contributes to one and only one cell, because two of the control animals were each inadvertently drawn twice from their pen. None of the animals classified as controls developed clinical disease prior to harvest. A $2 \times 4$ contingency table was used to test the four diplotypes combinations represented by at least ten animals ${ }^{13}$. The second evaluation for association of the EPAS1 T610/S610 variant with clinical disease was McNemar's test for correlated proportions ${ }^{14}$. This is the most appropriate test for paired nominal data.

\section{Results}

The 102 clinical BCHF cases and their penmate controls originated from 30 different sources, with the largest single source contributing 32 matched pairs (Table 1 and S1, see Underlying data). Although breed information was not available for many animals, the pairs were comprised of $100 \%$ polled, $93 \%$ solid black, and $70 \%$ male calves (Table $\mathrm{S} 1$, see Underlying data). Most of the 102 calves were from known, well-managed herds that focus on using Angus genetics. Clinical cases of BCHF were documented throughout all stages of calf fattening regimens (Figure 1). The most consistent signs at necropsy included: ventral and intermandibular edema, dilated pulmonary artery and right ventricle, and chronic passive congestion of the liver (Figure 2). The success of identifying BCHF cases was entirely dependent on highly trained, experienced pen riders. The false positive rate for pen rider-identified $\mathrm{BCHF}$ cases confirmed at necropsy was zero at sites NE01, NE04, and WY01; and 50\% at WY02 (three cases from six suspected cases). Together, samples from the 102 matched case-control pairs represent a resource for evaluating genetic, biochemical, and physiological questions about the mechanism of BCHF in feedlot cattle.
DNA samples from cases and controls were tested for association with known EPAS1 haplotypes according to the phylogenetic framework presented in Figure 3. Haplotype-phased protein variants (diplotypes) were unambiguously assigned for $98.5 \%$ of the animals (201/204, Table S1, see Underlying data). The frequency of the common, ancestral EPAS1 haplotype ('1') was nearly identical in the cases and controls (0.67). The T606/S610 variant reported to be dominantly associated with high-altitude pulmonary hypertension (haplotype ' 3 ') was less frequent in the cases $(0.21)$ than the controls $(0.25$, Table 2$)$. In addition, there was no statistical difference between four common diplotypes among the cases and controls in a Pearson's chi-square analysis (Table 3). However, the appropriate statistical test for paired nominal data is McNemar's test. This test with 45 discordant pairs showed the T606/S610 variant was not associated with BCHF (Table $4, \mathrm{OR}=0.73, p$-value $\left.=0.37, \mathrm{CI}_{95} 0.38-1.4\right)$. With 0.44

\section{Table 1. Feedlot sites and sources for case-control pairs.}

\begin{tabular}{|l|c|c|c|}
\hline Site $^{\mathrm{a}}$ & Altitude $\mathbf{m}(\mathbf{f t})$ & Pairs & Sources \\
\hline NE01 & $1,242(4,075)$ & 76 & 19 \\
\hline NE04 & $1,163(3,816)$ & 17 & 9 \\
\hline WY01 & $1,263(4,143)$ & 6 & 1 \\
\hline WY02 & $1,280(4,198)$ & 3 & 1 \\
\hline & Totals & 102 & 30 \\
\hline
\end{tabular}

aNE and WY sites were located in Nebraska and Wyoming, respectively
Day 1 (bull)
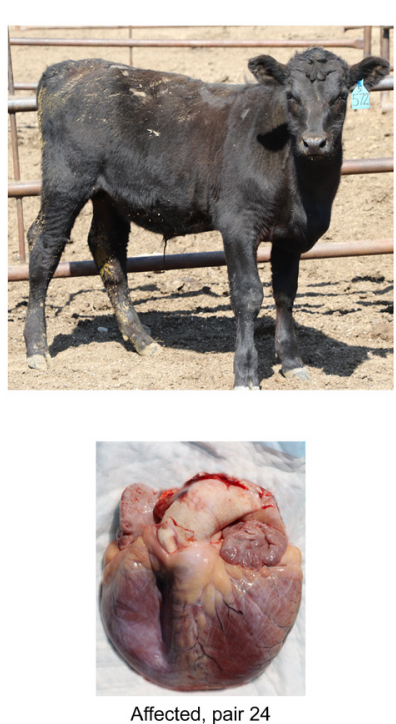

Day 30 (heifer)
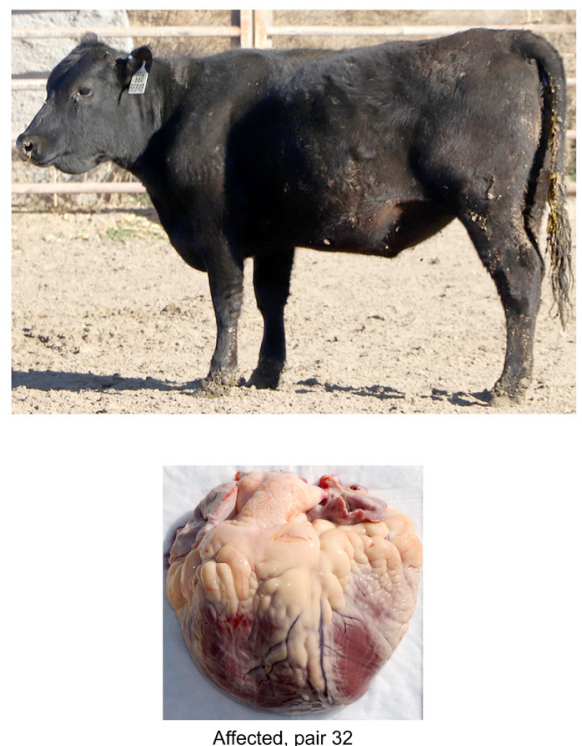

Day 238 (steer)

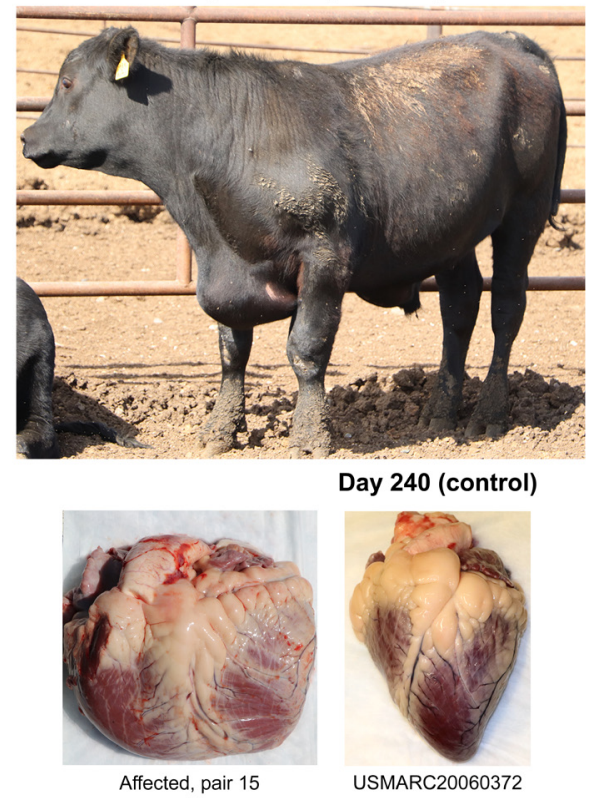

Figure 1. Bovine congestive heart failure (BCHF) clinical cases at different stages of fattening. Three types of animals identified by feedlot pen riders as end-stage heart failure candidates. Clinical cases were born and raised at 1,000 to 1,200 m prior to feedlot arrival. Their respective heart gross morphologies with enlarged right ventricles and pulmonary arteries are shown below each case. The control heart is from an Angus heifer fattened at $550 \mathrm{~m}$. 


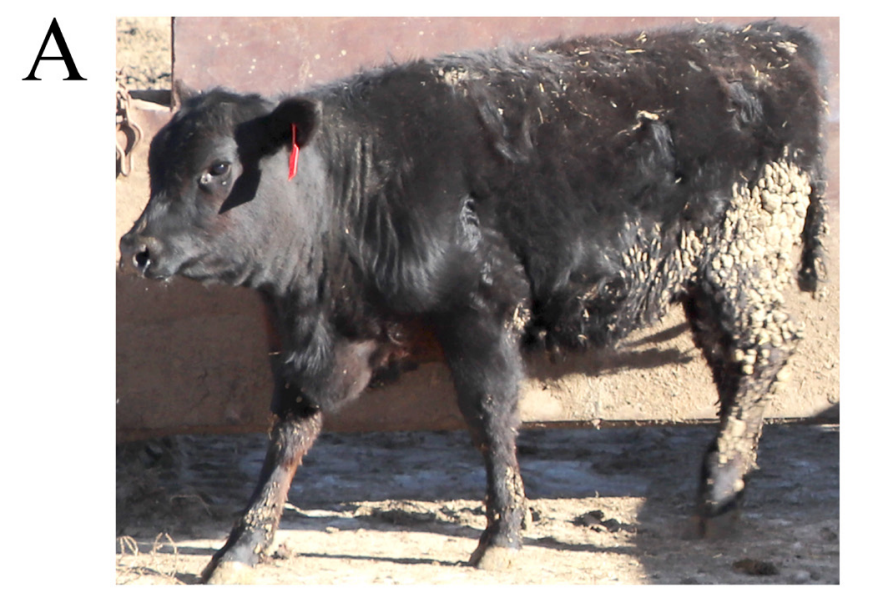

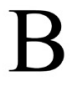
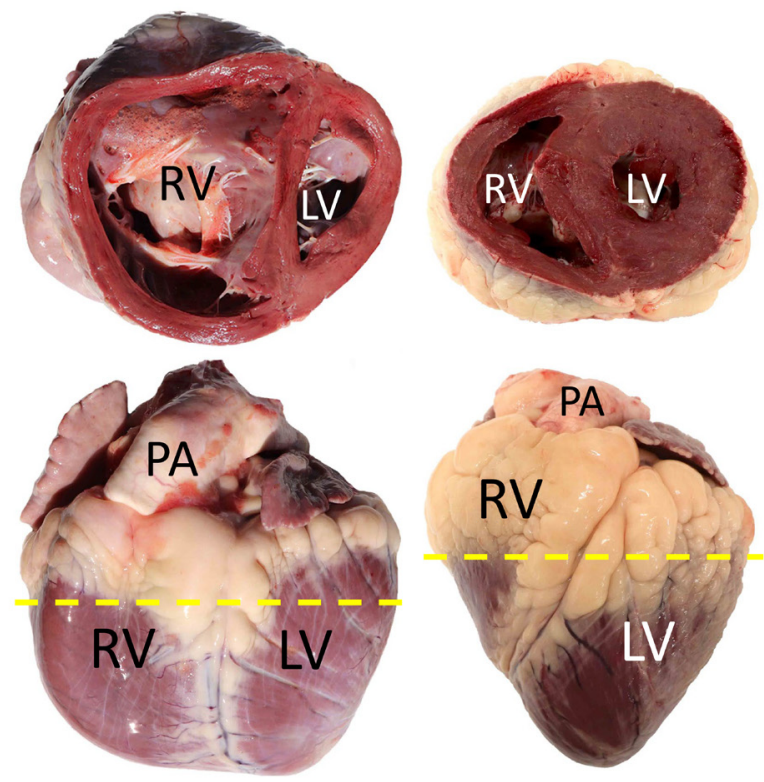

$\mathrm{C}$
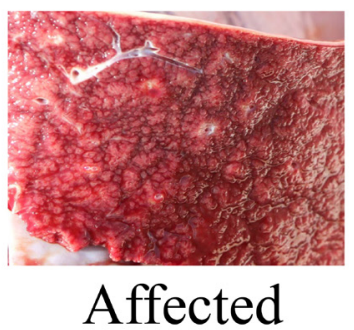

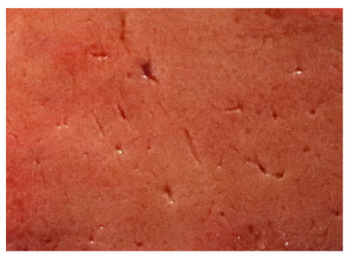

Unaffected

Figure 2. Gross morphological differences of a heart and liver in a representative bovine congestive heart failure (BCHF) clinical case. Panel A, affected heifer from (pair 77, Table S1) fattened at 1,200 m. Panel B, Gross heart morphology of affected heifer from pair 77 (left) and an unaffected Angus cow maintained for breeding at $578 \mathrm{~m}$ (right). The dashed line denotes where each heart was sectioned to show the dorsal half. Abbreviations: RV, right ventricle; LV, left ventricle; PA, pulmonary artery. Panel C, crosssection of the respective livers.

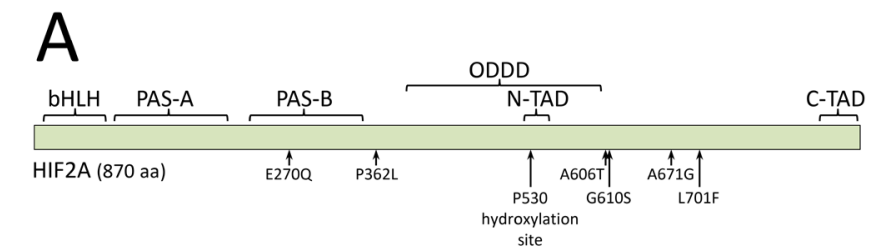

B

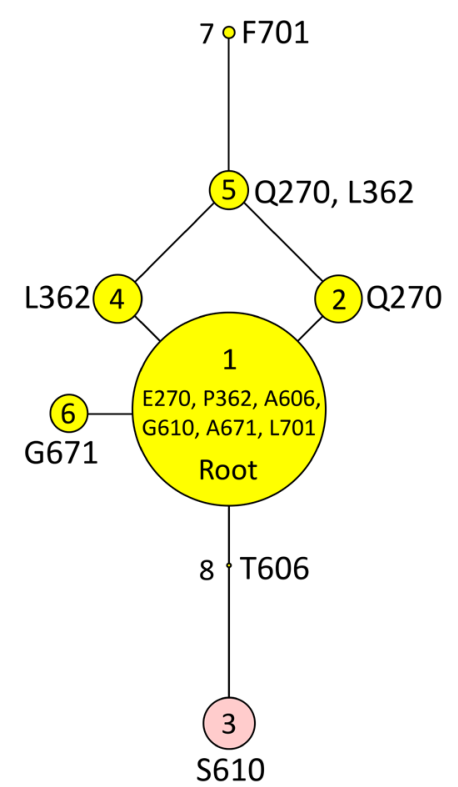

Figure 3. Physical map and rooted maximum parsimony phylogenetic tree of HIF2 $\alpha$ protein variants (EPAS1 haplotypes). Panel A, map of bovine HIF2 $\alpha$ domains in relationship to missense mutations found in cattle: bHLH, basic helix-loop-helix domain; PAS-A and PAS-B, Per-Arnt-Sim domains; ODDD, oxygendependent degradation domain; N-TAD, N-terminal transactivation domain; C-TAD, C-terminal transactivation domain. Panel B, HIF2 $\alpha$ polypeptide sequences encoded by haplotype variants. The areas of the circles are proportional to the variant frequency in a group of 1,250 cattle from 46 breeds with each node in the tree representing a different polypeptide sequence of HIF2 $\alpha$ that varies by one amino acid compared to adjacent nodes. Reproduced from Heaton et al., $2016^{9}$.

Table 2. EPAS1 haplotype frequencies among cases and controls.

\begin{tabular}{|c|l|c|c|}
\hline $\begin{array}{c}\text { Haplotype } \\
\text { code }\end{array}$ & $\begin{array}{l}\text { Distinguishing } \\
\text { Feature }\end{array}$ & Cases & Allele frequencies \\
\hline 1 & Ancestral & 0.667 & 0.672 \\
\hline 2 & Q270 & 0.059 & 0.034 \\
\hline 3 & T606, S610 & 0.206 & 0.250 \\
\hline 4 & L362 & -2 & - \\
\hline 5 & Q270, L362 & 0.005 & 0.020 \\
\hline 6 & G671 & 0.064 & 0.025 \\
\hline 7 & F701 & - & - \\
\hline
\end{tabular}

aNot detected 
Table 3. Pearson's chi-squared analysis of EPAS1 diplotypes among cases and controls.

\begin{tabular}{|c|c|c|c|c|c|c|c|c|c|}
\hline \multirow[b]{3}{*}{ Disease status } & \multicolumn{8}{|c|}{ EPAS1 diplotype ${ }^{a}$} & \\
\hline & \multicolumn{2}{|c|}{1,1} & \multicolumn{2}{|c|}{1,2} & \multicolumn{2}{|c|}{1,3} & \multicolumn{2}{|c|}{1,6} & \\
\hline & Obs. & $X^{2}$ & Obs. & $X^{2}$ & Obs. & $X^{2}$ & Obs. & $X^{2}$ & Totals \\
\hline Affected & 43 & 0.05 & 11 & 0.67 & 30 & 0.34 & 8 & 1.07 & 92 \\
\hline Unaffected & 45 & 0.05 & 6 & 0.69 & 36 & 0.35 & 3 & 1.09 & 90 \\
\hline Totals $^{b}$ & 88 & & 17 & & 66 & & 11 & & 182 \\
\hline
\end{tabular}

aDiplotypes not shown had less than ten total observations and thus were omitted from the analysis.

'The chi-square statistic was 4.3 and the $p$-value was 0.23 .

\section{Table 4. McNemar's test with EPAS1 T606/S610 and Q270 variants.}

\begin{tabular}{|l|c|c|}
\hline & \multicolumn{2}{c|}{ Risk factor present $^{\text {a }}$} \\
\hline Matched pairs & T606/S610 & Q270 \\
\hline Case (1), Control (0) & 19 pairs & 10 pairs \\
\hline Case (0), Control (1) & 26 pairs & 5 pairs \\
\hline Odds ratio & 0.73 & 2.0 \\
\hline p-value & $0.37^{\circ}$ & $0.30^{\circ}$ \\
\hline $95 \% \mathrm{Cl}$ & $0.38-1.4$ & $0.62-7.4$ \\
\hline
\end{tabular}

The risk factor was defined as having one or two copies of the EPAS1 variant.

'The '(1)' and '(0)' indicate the presence or absence of the risk factor, respectively.

'The $p$-value is the probability of observing this distribution of discordant pairs if there was no association between risk factor and disease.

discordant pairs having the T606/S610 variant, the sample size of 102 pairs achieved $80 \%$ power to detect an odds ratio of 2.5 using a two-sided McNemar test with a significance level of 0.05 . Frequencies of three other EPAS1 haplotype variants (Q270, L362, and G671) were less than 0.05 and too rare to analyze with a McNemar test. Thus, an association with EPAS1 haplotype variants was not detected with $\mathrm{BCHF}$ in these cattle.

\section{Discussion}

The present report describes a set of 102 clinical cases of BCHF and their matched controls collected from U.S. feedlots where outbreaks were severe and ongoing. Genetic analyses of EPAS1 variants did not show an association with BCHF. This result was significant because cases were closely matched with unaffected penmate controls from the same source, sex, breed type, arrival date, and management conditions. In some pairs, ear tag information suggested that animals shared the same sire. Case-control studies are a common and efficient means of studying diseases with a low prevalence and the McNemar's test is the appropriate statistical test for use on paired nominal data $^{15}$. A major advantage of the present design was the ability to increase the frequency of a potential genetic risk factor with relatively few participants (102 cases), while still evaluating more than 10,000 animals per feedlot site for disease. Nevertheless, results presented here suggest it is unlikely that genetic variation at the EPAS1 locus was a significant genetic risk factor for BCHF in these cattle.

The lack of EPAS1 association with BCHF is inconsistent with that reported in 2015 by Newman et al. for cattle with high-altitude pulmonary hypertension ${ }^{8}$. However, there were important differences in the cattle types, age, environment, and clinical definitions between the two studies. Animals in the 2015 study were mature, pastured cattle, maintained at 1,478 to $2,618 \mathrm{~m}$, and had pulmonary arterial hypertension, as measured by heart catheterization. In the present study, animals were yearling steers and heifers, raised and fattened at approximately 1,200 m, and had end-stage heart failure. Thus, it is possible that the animals in these respective studies are suffering from similar but different diseases. Another possibility is the cattle described by Newman et al. were affected by a right-sided ventricular heart failure initiated by hypobaric hypoxia, whereas the cattle in the present study had a left-sided ventricular failure, resulting in tissue hypoxia and subsequent BCHF. The latter was reported in 2019 in cattle fattened at $1,200 \mathrm{~m}$ suffering end-stage heart failure ${ }^{6}$. However, it is unknown whether the disease pathogenesis was a distinguishing factor in these studies. One remarkable feature of the BCHF clinical cases in the present study were those displaying signs of the disease at feedlot arrival and soon after. This is consistent with the hypothesis that fattening is not the underlying cause of disease in these cattle.

\section{Conclusions}

Protein variants encoded by EPAS1 haplotypes were not significantly associated with BCHF in fattened cattle at moderate altitudes in the North American Western Plains. Thus, identifying the genetic risk factors underlying this form of the disease may require a wider search. 


\section{Data availability}

Underlying data

Figshare: Table S1. Metadata and phased EPAS1 diplotypes for 102 case-control pairs. https://doi.org/10.6084/m9.figshare. 8862089.v1 ${ }^{16}$

\section{Extended data}

Figshare: Table S2. Summary of 36 possible EPAS1 diplotypes and their frequency in cases and controls. https://doi.org/10.6084/ m9.figshare.8862152.v1 $1^{17}$

Figshare: Table S3. EPAS1 haplotype frequencies in cases and controls. https://doi.org/10.6084/m9.figshare.8862179.v1 ${ }^{18}$

Figshare: Table S4. EPAS1 risk factor scoring used in McNemar's Test with 102 matched pairs. https://doi.org/10.6084/ m9.figshare.8862200.v $1^{19}$

Data are available under the terms of the Creative Commons Zero "No rights reserved" data waiver (CCO 1.0 Public domain dedication)
Grant information

Funding for this research was provided by the USDA, ARS appropriated projects [5438-32000-033-00D] (MPH) and The University of Nebraska Great Plains Veterinary Educational Center [2162390003] (DMG, BLVL) and the Nebraska Beef Industry Endowment [2662390323001] (BLVL).

Acknowledgments

We thank D. George, D. Ridgway, and S. Schmidt for secretarial and administrative support; S. Johnson for sample collection support; R. Carman, G. Darnall, P. Miller, T. Williams, and their outstanding pen riders for identifying clinical cases, assisting with sample acquisition, and sharing their knowledge. We also thank former USMARC Director, Dr. J. Pollak for leadership and support in the design and execution of this research project. Mention of trade names or commercial products in this publication is solely for the purpose of providing specific information and does not imply recommendation or endorsement by the U.S. Department of Agriculture. The USDA is an equal opportunity provider and employer.
1. Glover GH, Newsom LE: Brisket disease (dropsy of high altitude). Colorado Agricultural Experiment Station. 1915; 204: 3-24. Reference Source

2. Glover GH, Newsom LE: Further Studies on brisket disease. Journal of Agricultural Records. Washington, DC. 1918; XV(7): 409-13. Reference Source

3. Hecht HH, Kuida H, Lange RL, et al.: Brisket disease. III. Clinical features and hemodynamic observations in altitude-dependent right heart failure of cattle. Am J Med. 1962; 32: 171-83. PubMed Abstract | Publisher Full Text

4. Jensen R, Pierson RE, Braddy PM, et al.: Brisket disease in yearling feedlot cattle. J Am Vet Med Assoc. 1976; 169(5): 515-7. PubMed Abstract

5. Neary JM, Booker CW, Wildman BK, et al:: Right-Sided Congestive Heart Failure in North American Feedlot Cattle. J Vet Intern Med. 2016; 30(1): 326-34.

PubMed Abstract | Publisher Full Text | Free Full Text

6. Krafsur GM, Neary JM, Garry F, et al:: Cardiopulmonary remodeling in fattened beef cattle: a naturally occurring large animal model of obesity-associated pulmonary hypertension with left heart disease. Pulm Circ. 2019; 9(1): 2045894018796804.

PubMed Abstract | Publisher Full Text | Free Full Text

7. Moxley RA, Smith DR, Grotelueschen DM, et al:: Investigation of congestive heart failure in beef cattle in a feedyard at a moderate altitude in western Nebraska. J Vet Diagn Invest. 2019; 31(4): 509-522. PubMed Abstract | Publisher Full Text

8. Newman JH, Holt TN, Cogan JD, et al.: Increased prevalence of EPAS1 variant in cattle with high-altitude pulmonary hypertension. Nat Commun. 2015; 6: 6863. PubMed Abstract | Publisher Full Text | Free Full Text

9. Heaton MP Smith TP, Carnahan JK, et al: Using diverse U.S. beef cattle genomes to identify missense mutations in EPAS1, a gene associated with pulmonary hypertension [version 2; peer review: 2 approved]. F100ORes. 2016;
5: 2003.

PubMed Abstract | Publisher Full Text | Free Full Text

10. Neary JM, Gould DH, Garry FB, et al:: An investigation into beef calf mortality on five high-altitude ranches that selected sires with low pulmonary arterial pressures for over 20 years. J Vet Diagn Invest. 2013; 25(2): 210-8. PubMed Abstract | Publisher Full Text

11. Jensen R, Mackey DR: Diseases of feedlot cattle. 3d ed. Philadelphia: Lea \& Febiger. 1979; viii: 300

12. Heaton MP, Keele JW, Harhay GP, et al:: Prevalence of the prion protein gene E211K variant in U.S. cattle. BMC Vet Res. 2008; 4: 25 PubMed Abstract | Publisher Full Text | Free Full Text

13. Preacher KJ: Calculation for the chi-square test: An interactive calculation tool for chi-square tests of goodness of fit and independence. 2001. Reference Source

14. McNemar Q: Note on the sampling error of the difference between correlated proportions or percentages. Psychometrika. 1947; 12(2): 153-7. PubMed Abstract | Publisher Full Text

15. Niven DJ, Berthiaume LR, Fick GH, et al:: Matched case-control studies: a review of reported statistical methodology. Clin Epidemiol. 2012; 4: 99-110. PubMed Abstract | Publisher Full Text | Free Full Text

16. Heaton M: Table S1. Metadata and phased EPAS1 diplotypes for 102 casecontrol pairs. 2019. http://www.doi.org/10.6084/m9.figshare.8862089.v1

17. Heaton M: Table S2. Summary of $\mathbf{3 6}$ possible EPAS1 diplotypes and their frequency in cases and controls. 2019. http://www.doi.org/10.6084/m9.figshare.8862152.v1

18. Heaton M: Table S3. EPAS1 haplotype frequencies in cases and controls. 2019. http://www.doi.org/10.6084/m9.figshare.8862179.v1

19. Heaton M: Table S4. EPAS1 risk factor scoring used in McNemar's Test with 102 matched pairs. 2019

http://www.doi.org/10.6084/m9.figshare.8862200.v1 


\section{Open Peer Review}

\section{Current Peer Review Status:}

\section{Version 1}

Reviewer Report 13 September 2019

https://doi.org/10.5256/f1000research.21898.r52934

(C) 2019 Garry F. This is an open access peer review report distributed under the terms of the Creative Commons Attribution License, which permits unrestricted use, distribution, and reproduction in any medium, provided the original work is properly cited.

\section{Franklyn B. Garry}

Integrated Livestock Management, College of Veterinary Medicine and Biomedical Sciences, Colorado State University, Fort Collins, CO, USA

This is an excellent report that investigated whether a specific genetic factor is involved in the development of an increasingly important disease of feedlot animals managed at moderate altitudes. It is scientifically sound and well written. The disease condition is Bovine congestive heart failure, which is clinically similar to altitude-induced pulmonary hypertension with cor pulmonale and right heart failure, commonly known as High Altitude disease or Brisket disease. A previous investigation suggested that a variant of EPAS1 was strongly associated with the development of Brisket disease. This investigation explored whether that gene was associated with BCHF.

This was a case control study that was well designed and described. The explanation of experimental and statistical methods and results was very clear.

This is an important area of inquiry because BCHF is an important disease problem with significant impact on feedlot producers, for which there are currently no good preventive, management or treatment practices. Previous work has shown that there are significant differences in the pathologic findings of animals affected by BCHF versus Brisket disease, and this project shows that the genetic basis of the two problems is also likely to be different.

The authors describe that tissues were collected from some unaffected animals at slaughter, but there was no description of what analyses were performed on these tissues. I am assuming these were used to assess gross morphologic changes in comparison to the tissues of affected animals at necropsy, but this was not described.

There is a typographical error in the last sentence of the second paragraph of the Methods section, written as 'congesting' rather than 'congestive'.

Is the work clearly and accurately presented and does it cite the current literature? 
Yes

Is the study design appropriate and is the work technically sound?

Yes

Are sufficient details of methods and analysis provided to allow replication by others? Yes

If applicable, is the statistical analysis and its interpretation appropriate?

Yes

Are all the source data underlying the results available to ensure full reproducibility? Yes

Are the conclusions drawn adequately supported by the results?

Yes

Competing Interests: No competing interests were disclosed.

Reviewer Expertise: Bovine health and management, bovine pulmonary hypertension

I confirm that I have read this submission and believe that I have an appropriate level of expertise to confirm that it is of an acceptable scientific standard.

Reviewer Report 03 September 2019

https://doi.org/10.5256/f1000research.21898.r52931

(C) 2019 Clark E. This is an open access peer review report distributed under the terms of the Creative Commons Attribution License, which permits unrestricted use, distribution, and reproduction in any medium, provided the original work is properly cited.

\section{Emily L. Clark}

The Roslin Institute, Royal (Dick) School of Veterinary Studies, University of Edinburgh, Midlothian, UK

The aim of the study described in this manuscript was to evaluate a known genetic risk factor for $\mathrm{BCHF}$ in feedlot cattle raised at moderate altitudes by screening of EPAS1 haplotypes in paired cases and controls.

$\mathrm{BCHF}$ is a costly health problem for cattle producers in the Western Plains with losses exceeding $\$ 250,000$ annually and a 11 in 10,000 animal mortality rate. Consequently, reducing the impact of $\mathrm{BCHF}$ is a high priority. A potential genetic risk factor for $\mathrm{BCHF}$ was reported in 2015 for cattle with high-altitude pulmonary hypertension (1,478 to 2,618 $\mathrm{m}$ ) but it was unclear at the outset of this study whether this genetic risk was also prevalent in feed-lot cattle at moderate altitudes. 
The authors indicate that "Affected cattle were typically bred and managed with the aim of achieving high carcass quality." Presumably this could indicate there is some pleiotrophic effect of a gene influencing both traits and/or other concomitant traits? Or at least breeding for high carcass quality or other traits might be antagonistic to BCHF prevalence? As such measuring gene expression in lung, liver and heart in affected and unaffected animals in future studies may yield additional information particularly in the pathways that are involved in the disease; I assume the authors might already be working on this.

The experimental design is clear but defining "pen-matched" and "pen mate" unaffected controls at the first mention in the animal and study design would be helpful to the reader.

When the authors indicate that when an animal died naturally this "provided a window of opportunity to collect fresh samples immediately after euthanasia.", could they provide details of which tissues they collected? Were tissues collected for RNA as well as DNA for genotyping? Presumably samples were also collected for pathology but this isn't mentioned here.

Similarly for "Control tissue samples were collected from non-affected penmates", was this just ear tissue as mentioned in the methodology or other tissues, which could be used for RNA-Seq and gross pathology/histology?

"Hearts, livers, blood, and ear notches from unaffected cattle were collected during federally-inspected beef processing at the U.S. Meat Animal Research Center abattoir from six purebred Angus heifers raised and fattened at $578 \mathrm{~m}$ and 15 purebred Angus cows maintained for breeding at $578 \mathrm{~m}$." It needs to be clear from this sentence that these were for visual and gross morphological comparison with affected BCHF organs, as this only becomes obvious in Figure 1.

Similarly in figure 2 it is clear that heart and liver were collected to assess gross morphological differences between affected and unaffected animals but this isn't clear from the animal and study design section.

As a general comment to summarise the above comments relating to the sample collection could the authors clarify in the animal and study design section which tissues were collected and from which groups of animals in the text, and provide additional details in the form of a table in "underlying data" if necessary? This is particularly important because as the authors suggest the samples and information from these cattle are themselves a very useful resource for studying the disease, and knowing exactly which samples have been collected might reduce the chance of duplicated effort in the future.

Technically I believe the results section of this manuscript is sound. The methodology for genotyping using a custom iPLEX gold genotyping array for the six EPAS1 missense SNPS has been evaluated in previous studies by the authors and to the best of my knowledge the statistical tests used to analyse the results have been interpreted accurately.

In the discussion the authors mention "In some pairs, ear tag information suggested that animals shared the same sire." What was the proportion of the total number of animals that 
shared the same sire? Is it possible to determine how many different sires produced the 102 cases and matched pairs? Were any animals included in the study twins? I am not sure of the twinning rate in these cattle, I assume it might be quite low, but are there ever cases where one twin is affected by BCHF and the other unaffected?

The lack of an association with the EPAS1 haplotype variants and BCHF, in the feed lot cattle raised at moderate altitude included in this study, is a negative but nevertheless important result, that will be informative to producers, given the importance of $\mathrm{BCHF}$.

This is a well-designed and executed study that has been presented clearly and informatively by the authors.

Is the work clearly and accurately presented and does it cite the current literature? Yes

Is the study design appropriate and is the work technically sound?

Yes

Are sufficient details of methods and analysis provided to allow replication by others? Yes

If applicable, is the statistical analysis and its interpretation appropriate? Yes

Are all the source data underlying the results available to ensure full reproducibility? Yes

Are the conclusions drawn adequately supported by the results?

Yes

Competing Interests: No competing interests were disclosed.

Reviewer Expertise: Transcriptomics, ruminants, functional genomics, FAANG, gene expression, livestock

I confirm that I have read this submission and believe that I have an appropriate level of expertise to confirm that it is of an acceptable scientific standard.

Reviewer Report 27 August 2019

https://doi.org/10.5256/f1000research.21898.r52928

(C) 2019 Berry D. This is an open access peer review report distributed under the terms of the Creative Commons Attribution License, which permits unrestricted use, distribution, and reproduction in any medium, provided the original work is properly cited. 
Donagh P. Berry

Animal and Grassland Research and Innovation Centre, Teagasc, Fermoy, Ireland

The report is extremely well written and of high quality; crucially important that "negative results" are still published. In the abstract please clarify that the $n=102$ is 102 pairs - it a bit ambiguous. it would have been nice to genotype the animals on some for of SNP chip to determine the breed composition (you allude to not knowing) and also the pedigree structure (may influence your analysis). Other than for breeding purposes (end of the introduction) the results of such an approach can be used for personalised management (including purchasing). please re-write the 7 th line of the second paragraph in the M\&M; i can't understand what is being said - maybe there is a missing word or two

Is the work clearly and accurately presented and does it cite the current literature? Yes

Is the study design appropriate and is the work technically sound?

Yes

Are sufficient details of methods and analysis provided to allow replication by others?

Yes

If applicable, is the statistical analysis and its interpretation appropriate? Yes

Are all the source data underlying the results available to ensure full reproducibility? Yes

Are the conclusions drawn adequately supported by the results?

Yes

Competing Interests: No competing interests were disclosed.

Reviewer Expertise: genetic, genomics

I confirm that I have read this submission and believe that I have an appropriate level of expertise to confirm that it is of an acceptable scientific standard. 
The benefits of publishing with F1000Research:

- Your article is published within days, with no editorial bias

- You can publish traditional articles, null/negative results, case reports, data notes and more

- The peer review process is transparent and collaborative

- Your article is indexed in PubMed after passing peer review

- Dedicated customer support at every stage

For pre-submission enquiries, contact research@f1000.com 